\title{
Biochemical Attributes of Mithun Semen
}

\author{
P. Perumal
}

ICAR-National Research Centre on Mithun, Jharnapani, Nagaland (797 106), India

\section{Corresponding Author}

P. Perumal

e-mail: perumalponraj@gmail.com

\author{
Article History \\ Article ID: 3C0280j \\ Received in $01^{\text {st }}$ October, 2017 \\ Received in revised form $18^{\text {th }}$ November, 2017 \\ Accepted in final form $3^{\text {rd }}$ December, 2017
}

\begin{abstract}
The present study was designed to estimate the biochemical attributes of good and poor quality mithun semen. Fifty ejaculates (twenty five each for good and poor quality ejaculates) were collected from matured mithun bulls. Biochemical attributes such as alkaline phosphatase (ALP), acid phosphatase (ACP), aspartate aminotransferase (AST), alanine aminotransferase (ALT), lactic acid dehydrogenase (LDH), calcium (Ca), magnesium (Mg), zinc (Zn), chloride, citric acid, total seminal plasma protein (TSPP), inorganic phosphorous (IP), fructose and cholesterol in sperm were estimated. The result revealed that these attributes were varied significantly $(p<0.05)$ between the good and poor quality ejaculates. Good quality ejaculates has significantly $(p<0.05)$ higher ALP, ACP, LDH, Ca, Mg, Zn, citric acid, TSPP, IP, fructose and cholesterol and has significantly $(p<0.05)$ lower value in chloride concentration than in poor quality ejaculates. Moreover, there was positive correlation among the biochemical attributes such as ALP, ACP, LDH, Ca, Mg, Zn, CA, TSPP, IP, fructose, cholesterol and these attributes were negatively correlated with AST, ALT and chloride in both good and poor quality ejaculates. It was concluded that most of the biochemical attributes were higher in good quality than in poor quality ejaculates, indicated that former has structural stability than the latter that leads to former sperm has higher functional structures to move faster and in forward direction.
\end{abstract}

Keywords: Mithun, biochemical profiles, good and poor quality ejaculates

\section{Introduction}

Mithun (Bos frontalis) is a semi-wild, free-range mountain cattle available in the states of Arunachal Pradesh, Nagaland, Manipur and Mizoram of North-Eastern Hill (NEH) region of India and was originated more than 8000 years ago from wild Indian gaur. The animal occupies an important place in the socio-cultural and economic life of the tribal population and its population is decreasing as per the $19^{\text {th }}$ livestock census of India (2012) due to various reasons such as insufficient number of breeding bulls, increase in intensive inbreeding practices and lack of proper breeding management. Dwindling population of mithun is a cause of concern requiring greater effort from all quarters to conserve the species bearing much effect on the socio-economic status of tribals. Since mithuns are semi wild, mithun are following natural breeding with accompanied limitations such as cost and disease transmission. Under such circumstances, wider application of artificial breeding of mithun appears a viable option for conserving the species.

The seminal plasma is a highly complex biological fluid, secreted from various accessory sex glands and testes and contains various biochemical constituents such as cholesterol, sugars, proteins, metabolic, intra cellular and antioxidant enzymes, mineral elements (Rajoriya et al., 2013). The constituents of seminal plasma have various functions such acquisition of motility, capacitation, acrosome reaction and fertilizing capacity of spermatozoa (Perumal, 2014a). Various factors such as vaccination (Perumal et al., 2013a; Perumal et al., 2013b; Peruma, 2014a; Perumal, 2014b), seasons (Perumal et al., 2015; Rajoriya et al., 2016; Perumal et al., 2017a; Perumal et al., 2017b), pathological condition of reproductive system (Perumal, 2013; Perumal et al., 2013c; Perumal et al., 2016b), inclusion of additives (Perumal et a., 2012a; Perumal et al., 2012b) and hereditary and congenital causes (Perumal et al., 2012c) are affect the semen production and its quality. Several studies were conducted on composition of seminal plasma in different domestic animal species (Rajoriya et al., 2013; Perumal, 2014a). Further, perusal of literatures revealed meagre information on the composition of seminal plasma in mithun bulls. Therefore, the study was aimed to measure the biochemical composition of seminal plasma in mithun species for future semen preservation.

\section{Materials and Methods}

Apparently healthy mithun bulls $(n=10)$ of 3 to $5 \mathrm{yr}$ of age were selected from the herd in mithun farm, ICAR- NRC on Mithun, Jharnapani, Nagaland. The average body weight was 
$501 \mathrm{~kg}(493-507 \mathrm{~kg}$ ) with good body condition (score 5-6) maintained under uniform feeding (as per farm schedule) and managemental conditions. A total of 50 ejaculates were collected through rectal massage method. These ejaculates were splited into good and poor quality based on the certain fresh seminal criteria such as mass activity and individual motility. Mass activity, 3+ and above and individual motility, $70 \%$ and above were considered as good quality ejaculates whereas less than $3+$ and $70 \%$, respectively were considered as poor quality ejaculates.

The biochemical attributes such as ALP, ACP, AST, ALT, LDH activity, $\mathrm{Ca}, \mathrm{Mg}, \mathrm{Zn}, \mathrm{Na}, \mathrm{K}, \mathrm{IP}$, chloride, fructose, TSPP and cholesterol were measured by commercial available diagnostic kit. The results were analysed statistically between the good and poor quality ejaculates with the student ' $t$ ' test using the SPSS/PC (version 15.0; SPSS, Chicago, IL) and expressed as the mean \pm S.E.M. Significant difference values of $(p<0.05)$ were considered to be statistically significant after arcsine transformation of percentage data. Correlation among the biochemical attributes was estimated with Pearson's correlation coefficient. Differences at $(p<0.05)$ were considered to be statistically significant.

\section{Results and Discussion}

In the present experiment, the result revealed that these biochemical attributes were differed significantly $(p<0.05)$ between the good and poor quality semen samples (Table 1). Good quality ejaculates has significantly $(p<0.05)$ higher ALP, ACP, LDH, Ca, Mg, Zn, citric acid, TSPP, IP, fructose and cholesterol and significantly lower value in chloride concentration than in poor quality ejaculates. Moreover, there was a positive correlation among the biochemical attributes includes ALP, ACP, LDH, Ca, Mg, Zn, CA, TSPP, IP, fructose, cholesterol and these biochemical attributes were negatively correlated with AST, ALT and chloride in both good (Table 2) and poor quality (Table 3 ) ejaculates. Thus, it may improve the selection of the good quality ejaculates for preservation that used for artificial insemination.

Phosphatase enzymes (ALP and ACP) levels in seminal plasma are most essential for metabolism as well as functions of sperms (Perumal et al., 2015). So that, measurement of these enzymes have been recommended as the biomarkers for assessment of the quality of semen in mithun (Perumal et al., 2013; Perumal et al., 2016c; Baruah et al., 2016). ALP is primarily of testicular and epididymal origin and can be used as a clinical ejaculatory marker to differentiate azoospermia or oligospermia from ejaculatory failure (Perumal et al., 2015). In our experiment, the level of ALP was significantly decreased in the poor quality ejaculates than in good quality ejaculates (Pesch et al., 2006). ACP is mainly localized in corpus epididymidis, ductus epididymidis and vas deferens, but it is thought to be an indicator for the secretory function of prostate.
Table 1: Mean ( \pm S.E.) biochemical attributes of good and poor quality mithun semen

\begin{tabular}{|c|c|c|}
\hline Biochemical attributes & $\begin{array}{l}\text { Good quality se- } \\
\text { men }(n=25)\end{array}$ & $\begin{array}{l}\text { Poor quality } \\
\text { semen }(n=25)\end{array}$ \\
\hline ALP (KAU $\left.100 \mathrm{ml}^{-1}\right)$ & $225.78 \pm 3.67 a$ & $173.19 \pm 5.18 b$ \\
\hline ACP $\left(K A \cup 100 \mathrm{ml}^{-1}\right)$ & $243.92 \pm 3.84 a$ & $179.93 \pm 5.54 b$ \\
\hline AST $\left(\mu\right.$ mole $\left.^{-1}\right)$ & $80.55 \pm 1.64 a$ & $89.66 \pm 3.42 b$ \\
\hline $\operatorname{ALT}\left(\mu\right.$ mole $\left.^{-1}\right)$ & $13.54 \pm 1.26 a$ & $18.39 \pm 1.14 b$ \\
\hline $\operatorname{LDH}\left(I U ~^{-1}\right)$ & $306.57 \pm 4.41 \mathrm{a}$ & $237.88 \pm 6.88 b$ \\
\hline $\mathrm{Ca}\left(\mathrm{mg} \mathrm{dl^{-1 }}\right)$ & $32.45 \pm 2.44 a$ & $25.75 \pm 1.94 b$ \\
\hline $\mathrm{Mg}\left(\mathrm{mg} \mathrm{dl}{ }^{-1}\right)$ & $7.19 \pm 0.79 a$ & $5.28 \pm 0.88 b$ \\
\hline $\mathrm{Zn}\left(\mathrm{mg} \mathrm{dl^{-1 }}\right)$ & $3.76 \pm 0.64 a$ & $2.17 \pm 0.78 b$ \\
\hline Chloride $\left(\mathrm{mmol} \mathrm{I}^{-1}\right)$ & $319.81 \pm 3.37 a$ & $423.33 \pm 6.21 b$ \\
\hline Citric Acid (mg dl $\left.{ }^{-1}\right)$ & $534.05 \pm 6.26 a$ & $440.86 \pm 6.82 b$ \\
\hline Total Protein $\left(\mathrm{g} \mathrm{dl}^{-1}\right)$ & $8.28 \pm 0.95 a$ & $6.58 \pm 0.90 b$ \\
\hline $\begin{array}{l}\text { Inorganic Phosphorous } \\
\left(\mathrm{mg} \mathrm{dl}^{-1}\right)\end{array}$ & $8.67 \pm 1.14 a$ & $6.88 \pm 0.93 b$ \\
\hline Fructose $\left(\mathrm{mg} \mathrm{dl}^{-1}\right)$ & $503.34 \pm 5.65 a$ & $412.86 \pm 4.44 b$ \\
\hline $\begin{array}{l}\text { Cholesterol } \\
(\mu \mathrm{g} / 108 \text { sperm })\end{array}$ & $26.85 \pm 1.73 a$ & $23.011 .72 b$ \\
\hline
\end{tabular}

Means with different superscript within rows differ significantly $(p<0.05) ; \mathrm{n}=$ Number of ejaculates

Similar to phosphatse, transaminases are important in metabolic processes of sperm, which provide energy for motility, viability and fertilizing capability of spermatozoa and these transaminase activities in the ejaculates are good indicators of semen quality as these enzymes measure stability of sperm membrane (Perumal et al., 2015). Increasing abnormal sperm percentage in the ejaculate causes increased concentration of these transaminase enzymes in the extra cellular fluid is due to damage of sperm plasma membrane and leakage of enzymes from spermatozoa (Dogan et al., 2009). Moreover, increase the transaminases activities in the seminal plasma of poor quality ejaculates could be due to structural instability of the sperm or fragile nature of sperm membrane (Perumal et al., 2015) and less intactness of membrane of acrosome, plasma, mitochondria and flagella of the sperm.

Like transaminases, dehydrogenase such as LDH is also vital enzyme of almost universal distribution in the body which catalyses the reversible transamination of pyruvate to lactate. In sperm, it is chiefly located in the mid-piece region (Rajoriya et al., 2013) and it is also an essential metabolic enzyme, responsible for metabolic processes, which provide energy for viability, motility, capacitation and interaction with oocyte (Perumal et al., 2016a). It has been suggested that LDH of seminal fluid can be used as good indicator of sperm viability and membrane stability (Perumal et al., 2016a). Moreover, Pesch et al. (2006) observed that there 


\begin{tabular}{|c|c|c|c|c|c|c|c|c|c|c|c|c|c|c|c|}
\hline No & $\begin{array}{l}\text { Attri- } \\
\text { butes }\end{array}$ & 1 & 2 & 3 & 4 & 5 & 6 & 7 & 8 & 9 & 10 & 11 & 12 & 13 & 15 \\
\hline 1. & ALP & 1.00 & $0.94^{*}$ & $-0.86^{*}$ & $-0.85^{*}$ & $0.79^{*}$ & $0.85^{*}$ & $0.64^{*}$ & $0.69^{*}$ & $-0.78^{*}$ & $0.89^{*}$ & $0.90^{*}$ & $0.86^{*}$ & $0.89^{*}$ & $0.92^{*}$ \\
\hline 2. & $A C P$ & & 1.00 & $-0.83^{*}$ & $-0.81^{*}$ & $0.70^{*}$ & $0.82^{*}$ & $0.67^{*}$ & $0.71^{*}$ & $-0.75^{*}$ & $0.86^{*}$ & $0.86^{*}$ & $0.87^{*}$ & $0.86^{*}$ & $0.94^{*}$ \\
\hline 3. & AST & & & 1.00 & $0.92^{*}$ & $-0.84^{*}$ & $-0.87^{*}$ & $-0.65^{*}$ & $-0.76^{*}$ & $0.89^{*}$ & $-0.92^{*}$ & $-0.87^{*}$ & $-0.91^{*}$ & $-0.90^{*}$ & $-0.83^{*}$ \\
\hline 4. & ALT & & & & 1.00 & $-0.90^{*}$ & $-0.85^{*}$ & $-0.77^{*}$ & $-0.72^{*}$ & $0.85^{*}$ & $-0.94^{*}$ & $-0.92^{*}$ & $-0.93^{*}$ & $-0.94^{*}$ & $-0.92^{*}$ \\
\hline 5. & $\mathrm{LDH}$ & & & & & 1.00 & $0.82^{*}$ & $0.76^{*}$ & $0.66^{*}$ & $-0.80^{*}$ & $0.86^{*}$ & $0.88^{*}$ & $0.85^{*}$ & $0.87^{*}$ & $0.94^{*}$ \\
\hline 6. & $\mathrm{Ca}$ & & & & & & 1.00 & $0.78^{*}$ & $0.75^{*}$ & $-0.76^{*}$ & $0.85^{*}$ & $0.84^{*}$ & $0.86^{*}$ & $0.85^{*}$ & $0.95^{*}$ \\
\hline 7. & $\mathrm{Mg}$ & & & & & & & 1.00 & 0.67 & -0.64 & $0.76^{*}$ & $0.73^{*}$ & $0.78^{*}$ & $0.75^{*}$ & $0.93^{*}$ \\
\hline 8. & $\mathrm{Zn}$ & & & & & & & & 1.00 & $-0.83^{*}$ & $0.80^{*}$ & $0.78^{*}$ & $0.80^{*}$ & $0.85^{*}$ & $0.94^{*}$ \\
\hline 9. & $\mathrm{Cl}$ & & & & & & & & & 1.00 & $-0.89^{*}$ & $-0.86^{*}$ & $-0.87^{*}$ & $-0.96^{*}$ & $-0.84^{*}$ \\
\hline 10. & $\mathrm{CA}$ & & & & & & & & & & 1.00 & $0.95^{*}$ & $0.94^{*}$ & $0.97^{*}$ & $-0.23^{*}$ \\
\hline 11. & TP & & & & & & & & & & & 1.00 & $0.92^{*}$ & $0.95^{*}$ & $0.92^{*}$ \\
\hline 12. & IP & & & & & & & & & & & & 1.00 & $0.94^{*}$ & $0.95^{*}$ \\
\hline 13. & $F R$ & & & & & & & & & & & & & 1.00 & $0.93^{*}$ \\
\hline 15. & $\mathrm{CH}$ & & & & & & & & & & & & & & 1.00 \\
\hline
\end{tabular}

ALP: alkaline phosphatase, ACP: acid phosphatse, AST: aspartate aminotransferase, ALT: alanine aminotransferase, LDH: lactic acid dehydrogenase, $\mathrm{Ca}$ : calcium, Mg: magnesium, Zn: zinc, Cl: chloride, CA: citric acid, TP: total protein, IP: inorganic phosphate, FR: fructose, $\mathrm{CH}$ : cholesterol in sperm; * Correlation coefficient were significant, $p<0.05$

\begin{tabular}{|c|c|c|c|c|c|c|c|c|c|c|c|c|c|c|c|}
\hline No & $\begin{array}{l}\text { Attri- } \\
\text { butes }\end{array}$ & 1 & 2 & 3 & 4 & 5 & 6 & 7 & 8 & 9 & 10 & 11 & 12 & 13 & 15 \\
\hline 1. & ALP & 1.00 & $0.96^{*}$ & $-0.90^{*}$ & $-0.90^{*}$ & $0.93^{*}$ & $0.94^{*}$ & $0.95^{*}$ & $0.98^{*}$ & $-0.86^{*}$ & $0.82^{*}$ & $0.95^{*}$ & $0.96^{*}$ & $0.94^{*}$ & $0.95^{*}$ \\
\hline 2. & $\mathrm{ACP}$ & & 1.00 & $-0.89^{*}$ & $-0.89^{*}$ & $0.95^{*}$ & $0.96^{*}$ & $0.94^{*}$ & $0.96^{*}$ & $-0.85^{*}$ & $0.79^{*}$ & $0.96^{*}$ & $0.97^{*}$ & $0.95^{*}$ & $0.96^{*}$ \\
\hline 3. & AST & & & 1.00 & $0.86^{*}$ & $-0.91^{*}$ & $-0.90^{*}$ & $-0.84^{*}$ & $-0.90^{*}$ & $0.77^{*}$ & $-0.89^{*}$ & $-0.79^{*}$ & $-0.86^{*}$ & $-0.90^{*}$ & $-0.85^{*}$ \\
\hline 4. & ALT & & & & 1.00 & $-0.91^{*}$ & $-0.92^{*}$ & $-0.83^{*}$ & $-0.91^{*}$ & $0.79^{*}$ & $-0.90^{*}$ & $-0.84^{*}$ & $-0.90^{*}$ & $-0.91^{*}$ & $-0.90^{*}$ \\
\hline 5. & $\mathrm{LDH}$ & & & & & 1.00 & $0.93^{*}$ & $0.95^{*}$ & $0.96^{*}$ & $-0.86^{*}$ & $0.84^{*}$ & $0.95^{*}$ & $0.97^{*}$ & $0.96^{*}$ & $0.95^{*}$ \\
\hline 6. & $\mathrm{Ca}$ & & & & & & 1.00 & $0.94^{*}$ & $0.95^{*}$ & $-0.85^{*}$ & $0.82^{*}$ & $0.95^{*}$ & $0.96^{*}$ & $0.95^{*}$ & $0.96^{*}$ \\
\hline 7. & $\mathrm{Mg}$ & & & & & & & 1.00 & $0.95^{*}$ & $-0.84^{*}$ & $0.78^{*}$ & $0.95^{*}$ & $0.93^{*}$ & $0.97^{*}$ & $0.92^{*}$ \\
\hline 8. & $\mathrm{Zn}$ & & & & & & & & 1.00 & $-0.87^{*}$ & $0.83^{*}$ & $0.94^{*}$ & $0.96^{*}$ & $0.95^{*}$ & $0.95^{*}$ \\
\hline 9. & $\mathrm{Cl}$ & & & & & & & & & 1.00 & $-0.92^{*}$ & $-0.82^{*}$ & $-0.85^{*}$ & $-0.87^{*}$ & $-0.83^{*}$ \\
\hline 10. & $\mathrm{CA}$ & & & & & & & & & & 1.00 & $0.96^{*}$ & $0.93^{*}$ & $0.94^{*}$ & $-0.25^{*}$ \\
\hline 11. & TP & & & & & & & & & & & 1.00 & $0.95^{*}$ & $0.93^{*}$ & $0.94^{*}$ \\
\hline 12. & IP & & & & & & & & & & & & 1.00 & $0.95^{*}$ & $0.95^{*}$ \\
\hline 13. & FR & & & & & & & & & & & & & 1.00 & $0.96^{*}$ \\
\hline 15. & $\mathrm{CH}$ & & & & & & & & & & & & & & 1.00 \\
\hline
\end{tabular}

ALP: alkaline phosphatase, ACP: acid phosphatse, AST: aspartate aminotransferase, ALT: alanine aminotransferase, LDH: lactic acid dehydrogenase, $\mathrm{Ca}$ : calcium, Mg: magnesium, Zn: zinc, Cl: chloride, CA: citric acid, TP: total protein, IP: inorganic phosphate, FR: fructose, $\mathrm{CH}$ : cholesterol in sperm; * Correlation coefficient were significant, $p<0.05$

was positive correlation among LDH activities, total sperm motility, progressive motility and livability of sperm in fresh ejaculates, which may indicates that extracellular LDH ensures metabolism of spermatozoa. In the present study, extracellular LDH concentration was increased significantly $(p<0.05)$ in seminal plasma of good quality ejaculates than in 
poor quality ejaculates. It has thus been proposed that higher LDH levels in seminal plasma of fresh semen can be used as a good indicator of higher motility, progressive motility and living sperm of ejaculates (Rajoriya et al., 2013).

Mineral elements such as $\mathrm{Ca}, \mathrm{Mg}, \mathrm{Zn}$ and IP of ejaculate were significantly higher in good quality than in poor quality ejaculates, whereas concentration of chloride was higher in poor quality ejaculates. Zn plays an essential role in normal testicular development, spermatogenesis and sperm motility (Perumal, 2014a). It is also a cofactor for a number of metalloenzymes in animals. Zn plays an important role in prostate, epididymal and testicular functions (Ebisch et al., 2003). Zn has been reported to influence the process of spermatogenesis (Wong et al., 2002), controls sperm motility (Wroblewski et al., 2003), stability of sperm membrane (Kendall et al., 2000), preserves the ability of sperm nuclear chromatin to undergo decondensation and modulates sperm functions (Suruki et al., 1995). Hypozinkemia leads to gonad dysfunction, decreased testicular weight, atrophy of seminiferous tubules and complete cessation of spermatogenesis (Martin et al., 1994).

Calcium and $\mathrm{Mg}$ are required in many physiological processes as a regulator in all living cells, including spermatozoa. The presence of $\mathrm{Mg}^{2+}$ and $\mathrm{Ca}^{2+}$ ions is necessary for the last stage of capacitation, the following acrosome reaction and hyperactive motility of spermatozoa. Ca flux control through the spermatozoal membrane is essential for fertilization (Bailey and Buhr, 1993) and it was noticed that the inclusion of $\mathrm{Ca}^{2+}$ with calcimine to isolated ram caudal spermatozoa caused stimulation of flagellar beat activity (Bradley and Forrester, 1982). But negative correlation between Ca concentration in seminal plasma and motility of spermatozoa was also reported bovine spermatozoa (Machal et al., 2002). In the present study, concentration of $\mathrm{Ca}$ and $\mathrm{Mg}$ were significantly higher in good quality than in poor quality ejaculates as indicates that the Ca is positively correlated with sperm motility, viability and integrity of plasma and acrosomal membrane as Ca stabilizes the plasma membrane and influences its permeability and excitability. The higher correlation coefficient between seminal plasma Ca concentration and seminal plasma protein suggests that spermatozoon proteins as well as those of seminal plasma participate in extracellular Ca flow activation (Marques et al., 2000). Further, Ca is also required to stimulate the steriodogenesis in Leydig cells of the testis. Deficiency of $\mathrm{Ca}$ in the testes or accessory gland will leads to adverse effects on the normal function of the reproductive system and spermatogenesis (Kaplan et al., 1995).

Chloride levels were significantly $(p<0.05)$ higher in the poor quality ejaculates than in good quality ejaculates. The excess chloride could be toxic to bovine sperm which is neutralised by increased sodium levels (Perumal, 2014a). This could explain the reason for increased chloride in poor quality ejaculates. In poor quality ejaculates, seminal plasma fructose and metabolic enzyme concentrations are also low whereas chloride concentration is high (Hirsch et al., 1991). The low protein and high chloride content of the secretion is rather hostile to sperm. It is known that modulation of a variety of ion channels (like $\mathrm{Cl}$ ) of spermatozoa is a characteristic event associated with capacitation and acrosome reaction of mammalian spermatozoa (Barrier-Battut et al., 2002). Hence, increasing the $\mathrm{Cl}$ level in seminal plasma may play a role in infertility.

TSPP in the seminal plasma influences various functions of the sperm such as capacitation, acrosome reaction, motility, DNA integrity and fertilization of the oocyte (Moura et al., 2007). The level of TSPP in fresh semen of good quality ejaculates was significantly higher than in poor quality ejaculates. But some specific proteins might be responsible for the quality and freezability of semen which could not be differentiated between these two groups simply by measuring the total seminal plasma protein. Moreover, no report has so far been available on total seminal plasma protein level of good and poor quality ejaculates in mithun bull. Perumal (2014a) reported low mean protein value of static ejaculate than the motile ejaculate which supports the higher numerical value of TSPP in the highly motile samples in the present study. Similarly, Singh et al. (1989) reported a positive association of the protein values in the semen with its freezability. The reason could be the great importance of protein for motility and survival of spermatozoa during storage (Singh et al., 1989; Moura et al., 2007). Seminal plasm proteins are also known to have protective action towards sperm against lipid peroxidation (Schonek et al., 1996). But Mohanty (1999) reported higher TSPP in poor quality bulls than in good quality bulls. This difference could be due to difference in selection criteria of good and poor quality ejaculates, frequency of collection, method employed for estimation, age and number of bulls studied and season (Perumal, 2014a).

Fructose and citric acid are reported to play important roles in sperm motility and concentration, particularly with regard to energy metabolism, through glucose utilization (Videla et al., 1981). Fructose is one of the major energy yielding nutritive substrates present in seminal fluid (Gonzales and Villena, 1997). Fructose is secreted from the seminal vesicles and the accessory sex glands. It is the major carbohydrate found in seminal plasma, provides over half the spermatozoa carbohydrate consumption and appears essential for normal sperm motility. In the present study, the fructose and citric acid concentration were reduced significantly in poor quality ejaculates as indicates that the functions of accessory sex glands was affected as seminal fructose is positively correlated with semen volume and sperm motility (Saeed et al., 1994). The determination of fructose itself is of particular significant because there is a direct relationship between the fructose level in seminal plasma and the testosterone function of the interstitial cells of Leydig. Fructose values which fall below normal may be a consequence of inflammatory condition in the prostrate or seminal vesicles or structural abnormality of 
the seminal vesicles and their ducts (Schirren, 1983).

\section{Conclusion}

Most of the biochemical attributes were significantly higher in good quality in comparison to the poor quality ejaculates of mithun. This indicates that good quality sperm has higher structural stability than the poor quality sperm that leads to good quality sperm has higher functional sperm structures to move faster and in forward direction.

\section{References}

Bailey, J.L., Buhr, M.M., 1993. Cryopreservation alters the $\mathrm{Ca}^{2+}$ flux of bovine spermatozoa. Canadian Journal of Animal Science 74, 45-51.

Barrier-Battut, I., Delajarraud, H., Legrand, E., Buyas, J.F., Fieni, F., Tainturier, D., Thorin, C., Pouliquen, H., 2002. Calcium, magnesium, copper and zinc in seminal plasma of fertile stallions and their relationship with semen freezability. Theriogenology 58, 229-232.

Bradley, M.P., Forrester, I.T., 1982. Human and ram seminal plasma both contain a calcium-dependent regulator protein, calsemin. Journal of Andrology 3, 289-296.

Dogan, I., Polat, U., Nur, Z., 2009. Correlations between seminal plasma enzyme activities and semen parameters in seminal fluid of Arabian horses. Iranian Journal of Veterinary Research 10, 119-124.

Ebisch, T.M.W., Van Heerde, W.L., Thomos, C.M.G., Vander Put, N., Wong, W.Y., Steegers Theunissen, R.P.M., 2003. C677T methylene tetrahydrofolate reductase polymorphism interferes with effect of folic acid and zinc sulphate on sperm concentration. Fertility and Sterility 80, 1190-1194.

Gonzales, G.F., Villena, A., 1997. Influence of low corrected seminal fructose levels on sperm chromatin stability in semen from men attending an infertility service. Fertility and Sterility 67, 763-768.

Hirsch, I.H., Jeyendran, R.S., Sedor, J., Rosecrans, R.R., Staas, W.E., 1991. Biochemical analysis of electroejaculates in spinal cord injured men: comparison to normal ejaculates. Journal of Urology 145, 73-76.

Kaplan, A., Jack, R., Opheim, K.E., Toivola, B., Lyon, A.W., 1995. Mineral and trace elements. In: Clinical chemistry. 4th edn. Baltimore, Williams and Wilkins, 351-356.

Kendall, N.R., McMullan, S., Green, A., Rodway, R.G., 2000. Effect of zinc, cobalt and selenium soluble glass bolus on trace element status and semen quality of ram lambs. Animal Reproduction Science 62, 277-283.

Livestock Census (19 $)$, 2012. All India Report. Department of Animal Husbandry, Dairying and Fisheries, Krishi Bhawan, New Delhi, Ministry of Agriculture and Farmers Welfare, Government of India.

Machal, L., Chladek, G., Strakova, E., 2002. Copper, phosphorus and calcium in bovine blood and seminal plasma in relation to semen quality. Journal of Animal
Feed and Science 11, 425-435.

Marques, V.A., Goulart, L.R., Silva, A.E.D.F., 2000. Variations of protein profiles and calcium and phospholipase A2 concentrations in thawed bovine semen and their relation to acrosome reaction. Genetics and Molecular Biology 23, 825-829.

Martin, G.B., White, C.L., Markey, C.M., Blackberry, M.A., 1994. Effect of dietary zinc deficiency on the reproductive system of young male sheep: testicular growth and the secretion of inhibin and testosterone. Journal of Reproduction and Fertility 101, 87-96.

Mohanty, D.N., 1999. Studies on reproductive soundness, freezability and fertility in CB bulls. Thesis Ph.D. Deemed University, Indian Veterinary Research Institute, Izatnagar, India.

Moura, A.A., Chapman, D.A., Koc, H., Killian, G.C., 2007. A comprehensive proteomic analysis of the accessory sex gland fluid from mature Holstein Bulls. Animal Reproduction Science 98, 169-188.

Perumal, P., 2014a. Studies on effect of low density lipoprotein on freezability and fertilizing ability of spermatozoa in mithun (Bos frontalis) bulls. Ph.D. Thesis submitted to ICAR-Indian Veterinary Research Institute, Deemed University, Izatnagar, Bareilly, Uttar Pradesh, India.

Perumal, P., Chamuah, J.K., Nahak, A.K., Rajkhowa, C., 2015. Effect of melatonin on the liquid storage $\left(5^{\circ} \mathrm{C}\right)$ of semen with retrospective study of calving rate at different season in mithun (Bos frontalis). Asian Pacific Journal of Reproduction 4(1), 1-12.

Perumal, P., Srivastava, S.K., Ghosh, S.K., Baruah, K.K., Bag, S., Rajoriya, J.S., Kumar, K., Rajkhowa, C., Pande, M., Srivastava, N., 2016a. Low density lipoproteins as additive improves quality Parameters and biomarkers of oxidative stress following cryopreservation of mithun (Bos frontalis) spermatozoa. Reproduction in Domestic Animals 51, 708-716.

Perumal, P., Khate, K., Rajkhowa, C., 2013a. Effect of foot and mouth disease vaccination on seminal and biochemical profiles of mithun (Bos frontalis) semen. Asian Pacific Journal of Reproduction 2(3), 209-214.

Perumal, P., 2014b. Effect of foot and mouth disease vaccination on semen production in mithun (Bos frontalis). Journal of Research 1, 935.

Perumal, P., Vupru, K., Khate, K., Veeraselvam, M., Verma, A.K., 2013b. Effect of foot and mouth disease vaccination on the semen quality of mithun (Bos frontalis). Advances in Animal and Veterinary Sciences 1(5), 151-156.

Perumal, P., Savino, N., Sangma, C.T.R., Chang, S., Sangtam, T.Z.T., Khan, M.H., Singh, G., Brijesh Kumar, Yadav, D., Srivastava, N., 2017a. Effect of season and age on scrotal circumference, testicular parameters and endocrinological profiles in mithun bulls. Theriogenology 98, 23-29.

Perumal, P., Savino, N., Sangma, C.T.R., Khan, M.H., Ezung, 
E., Chang, S., Sangtam, T.Z.T., 2017b. Seasonal effect on physiological, reproductive and fertility profiles in breeding mithun bulls. Asian Pacific Journal of Reproduction 6(6), 268-278.

Perumal, P., 2013. Effect of unilateral cryptorchidism on seminal parameters of mithun (Bos frontalis). Indian Veterinary Journal 91(9), 43-46.

Perumal, P., Chang, S., Sangma, C.T.R., Khate, K., Saminathan, M., 2016b. Unilateral cryptorchidism on mobility and velocity parameters in mithun sperm. Journal of Experimental Biology and Agricultural Sciences 4(spl-3), S116-S122.

Perumal, P., Vupru, K., Khate, K., Veeraselvam, M., Verma, A.K., Nahak, A.K., Rajkhowa, C., 2013c. Spontaneous erection and masturbation in mithun (Bos frontalis) bulls. International Journal of Bio-Resource and Stress Management 4(4), 645-647.

Perumal, P, Barik, A.K., Mohanty, D.N., Das, S, Mishra, P.C., Chang, S., 2016c. Comparison of semen characteristics of good and poor freezable Jersey crossbred bulls. International Journal of Bio-resource and Stress Management 7(5), 1177-1180.

Perumal, P., Selvaraju, S., Barik, A.K., Mohanty, D.N., Das, S., Mishra, P.C., Veeraselvam, M., 2012a. Reduced glutathione and cysteine hydrochloride on sperm motility and velocity parameters of poor crossbred bull semen. International Journal of Bio-resource and Stress Management 3(2), 145-151.

Perumal, P., Selvaraju, S., Barik, A.K., Mohanty, D.N., Das, S., Mishra, P.C., Veeraselvam, M., 2012b. Cysteine Hydrochloride on Post-thawed Seminal Characters of Jersey Crossbred Bull. International Journal of Bioresource and Stress Management 3(2), 232-235.

Perumal, P., Srivastava, N., Srivastava, S.K., Chamuah, J.K., Veeraselvam, M., 2012c. Hereditary and congenital causes of infertility in buffalo (Bubalus bubalis) bulls. International Journal of Bio-resource and Stress Management 3(4), 472-480.

Pesch, S., Bergmann, M., Bostedt, H., 2006. Determination of some enzymes and macro and microelements in stallion seminal plasma and their correlations to semen quality. Theriogenology 66, 307-313.
Rajoriya, J.S., Prasad, J.K., Ghosh, S.K., Perumal, P., Anuj Kumar, Kaushal, S., Singh, M., 2013. Effects of seasons on enzymatic changes and cholesterol efflux in relation to freezability in Tharparkar bull semen. Asian Pacific Journal of Reproduction 2(4), 280-288.

Rajoriya, J.S., Kumar, S., Shinde, S., Kumar, A., Perumal, P., Chauhan, M., 2016. Effect of winter and summer season on lipid peroxidation and total seminal plasma protein of Tharparkar bull semen. International Journal of Bioresource and Stress Management 7(6), 1356-1360.

Saeed, S., Khan, F.A., Rehman, S.B., Khan, D.A., Ahmad, M., 1994. Biochemical parameters in evaluation of oligospermia. Journal of Pakistan Medical Association 44, 137-140.

Schirren, C., 1983. Textbook of practical Andrology. Schireng, A, G. Hamburg Germany, 17-31.

Schonek, C., Braun, J., Einspanier, R., 1996. Sperm viability is influenced by the bovine seminal plasma protein aSPF: effects on motility, mitochondrial activity and lipid peroxidation. Theriogenology 45, 633-642.

Singh, D.M., Pangawkar, G.R., Hundal, R.S., Chaudhary, K. C., 1989. Studies on certain biochemical constituents of seminal plasma in exotic and crossbred bulls. Indian Veterinary Journal 66, 1112-1115.

Suruki, T., Nakajima, K., Yamamoto, A., Yamanaka, H., 1995. Metallothionein binding zinc inhibits nuclear chromatin decondensation of human spermatozoa. Andrologia 27, 161-164.

Videla, E., Blanco, A.M., Galli, M.E., Fernandez-Collazo, E., 1981. Human seminal biochemistry: fructose, ascorbic acid, citric acid, acid phosphatase and their relationship with sperm count. Andrologia 13, 212-214.

Wong, W.Y., Merkus, H.M., Thomas, C.M., Menkveld, R., Zielthuis, G.A., Steegers-Theunissen, R.P., 2002. Effect of folic acid and zinc sulphate on male factor sub fertility, a double blind, randomized placed controlled trial. Fertility and Sterility 77, 491-498.

Wroblewski, N., Schill, W.B., Henkel, R., 2003. Metal chelators change the human sperms motility pattern. Fertility and Sterility 79, 1584-1589. 